\title{
Increased risk of internal tumors in DNA repair-deficient xeroderma pigmentosum patients: analysis of four international cohorts
}

\author{
Sergey Nikolaev ${ }^{1 *}$, Andrey A. Yurchenko ${ }^{1}$ and Alain Sarasin ${ }^{2 *}$ (1)
}

\begin{abstract}
Background: Xeroderma pigmentosum (XP) is a rare, autosomal, recessive DNA repair-deficiency disorder with a frequency of 1-3 per million livebirths in Europe and USA but with higher frequencies in isolated islands or in countries with a high level of consanguinity. XP is characterized by high incidence of skin cancers on sun-exposed sites. Recent improvement in life expectancy of XP patients suggests an increased risk of frequently aggressive and lethal internal tumors. Our purpose was to quantify relative risks of internal tumor development for XP patients by tumor type, XPsubtype, patients' ages and ethnicity through comparison with the US general population.

Methods: We analyzed four independent international well-characterized XP cohorts (from USA, UK, France and Brazil) with a total of 434 patients, where $11.3 \%$ developed internal tumors and compared them to the American general population. We also compiled, through PubMed/Medline, a dataset of 89 internal tumors in XP patients published between 1958 and 2020.

Results: In the combined 4-XP cohort, relative risk of internal tumors was 34 (95\% confidence interval (CI) 25-47) times higher than in the general population ( $p$-value $=1.0 \mathrm{E}-47)$ and tumor arose 50 years earlier. The XP-C group was at the highest risk for the $0-20$ years old-patients $(\mathrm{OR}=665 ; 95 \% \mathrm{Cl} 368-1200 ; p$-value $=4.3 \mathrm{E}-30)$. The highest risks were observed for tumors of central nervous system $(\mathrm{OR}=331 ; 95 \% \mathrm{Cl} 171-641 ; p$-value $=2.4 \mathrm{E}-20)$, hematological malignancies $(\mathrm{OR}=120 ; 95 \% \mathrm{Cl} 77-186 ; p$-value $=3.7 \mathrm{E}-36)$, thyroid $(\mathrm{OR}=74 ; 95 \% \mathrm{Cl} 31-179 ; p$-value $=1.2 \mathrm{E}-8)$ and gynecological tumors $(\mathrm{OR}=91 ; 95 \% \mathrm{Cl} 42-193 ; p$-value $=3.5 \mathrm{E}-12)$. The type of mutation on the XPC gene is associated with different classes of internal tumors. The majority of French XP-C patients (80\%) are originated from North Africa and carried the XPC delTG founder mutation specific from the South Mediterranean area. The OR is extremely high for young (0-20 years) patients with more than 1300-fold increase for the French XPs carrying the founder mutation.
\end{abstract}

Conclusion: Because the age of XP population is increasing due to better sun-protection and knowledge of the disease, these results are of particular importance for the physicians to help in early prevention and detection of internal tumors in their XP patients. Few preventive blood analyses or simple medical imaging may help to better detect early cancer appearance in this population.

\footnotetext{
*Correspondence: sergey.nikolaev@gustaveroussy.fr; alain.

sarasin@gustaveroussy.fr

${ }^{1}$ INSERM U981, Gustave Roussy Institute, Université Paris-Saclay, Villejuif, France

${ }^{2}$ Laboratory of Genome Integrity and Cancers, CNRS UMR9019, Gustave Roussy Institute, Université Paris-Saclay, 114 rue Edouard Vaillant,

94805 Villejuif, France
} permits use, sharing, adaptation, distribution and reproduction in any medium or format, as long as you give appropriate credit to the original author(s) and the source, provide a link to the Creative Commons licence, and indicate if changes were made. The images or other third party material in this article are included in the article's Creative Commons licence, unless indicated otherwise in a credit line to the material. If material is not included in the article's Creative Commons licence and your intended use is not permitted by statutory regulation or exceeds the permitted use, you will need to obtain permission directly from the copyright holder. To view a copy of this licence, visit http://creativecommons.org/licenses/by/4.0/. The Creative Commons Public Domain Dedication waiver (http://creativeco mmons.org/publicdomain/zero/1.0/) applies to the data made available in this article, unless otherwise stated in a credit line to the data. 
Keywords: Nucleotide excision repair, Transcription-coupled repair, Leukemia, UV-light, Internal cancers

\section{Introduction}

Xeroderma pigmentosum (XP) is an autosomal recessive disease, caused by deficient nucleotide excision repair (NER) [1-3]. XP is rare with an incidence of $1-3 / 1,000,000$ in Europe [4] and USA [5], while it is more common in some countries such as Japan [6], Pakistan [7] and Comoros [8]. One of the highest frequencies of XP patients (>100/1,000,000) is reported in North Africa and associated with high allelic frequency of a causative mutation in the population and with traditions of consanguinity [9]. Characteristic findings of $\mathrm{XP}$ include photosensitivity, actinic keratosis, cutaneous atrophy and early onset of cutaneous tumors [8, $10-13]$. There are seven complementation groups that are involved in the classical XP disease, caused by biallelic mutations in one of XPA, B, C, D, E, F, G genes $[12,14]$. The XP Variant (XP-V) is NER-proficient but is caused by mutations in the $P O L H$ gene coding the translesion DNA polymerase- $\eta[15,16]$.

NER is involved in repair of various bulky adducts besides UV-induced-photoproducts, such as those induced by genotoxins in cigarette smoke, genotoxic food contaminants or ROS-induced DNA damage [12]. We hypothesize that NER deficiency might also be a cause of increased risk of non-skin cancers. Indeed, a 12-fold increased frequency of developing internal neoplasms in XP was reported in the past [17]. In line with that, we described 25-fold increased mutation rates in leukemia developed by XP patients with a characteristic mutational profile [18].

In order to quantify the risk of internal tumors in the $\mathrm{XP}$ population, we analyzed data from 4 international clinically well-characterized XP cohorts. In parallel, we conducted a systematic research investigating all published reports on internal tumors (non-skin cancers) in XP patients since 1958.

\section{Method}

\section{Data sources}

We searched PubMed for "xeroderma pigmentosum" and analyzed papers describing non-redundant internal tumors. The first paper appeared in 1958 [19] and the latest is this one. We defined as internal tumors all described malignant tumors in XP patients except those due to sun exposure such as skin cancers. Lip and tongue tumors and cutaneous angiosarcoma have also been removed because they are partially linked to sun exposure [8]. We retrieved clinical descriptions, complementation groups and tumor characteristics in 88 XP patients (89 tumors) [20-45].

\section{French cohort}

Among $176 \mathrm{XP}$ patients diagnosed in our laboratory, we already described 23 internal tumors [18, 28, 29, 35, 42] and 9 new patients are reported here. All patients were followed in University hospitals in France and sometimes in North Africa. Skin biopsies or blood samples were sent to the Laboratory of DNA repair-deficient diseases at Gustave Roussy (Villejuif, France) or to the Hematology Center at Saint-Louis Hospital (Paris, France) for molecular diagnosis. DNA repair activities, determination of $\mathrm{XP}$ complementation groups, Sanger sequencing of XP genes were done as already published [8].

The French cohort is composed of 64\% XP-C patients (80\% of them are originated from North Africa), $18 \%$ are XP-V, 8.5\% are XP-D, 7.5\% are XP-A, 2 patients are XP-E, one patient is XP-F and one is XP-G.

Written informed consent was provided by patients or their relatives in accordance with the Declaration of Helsinki and French law. This study was approved by the Institutional Review Board of the University Institute of Hematology (IUH; Saint-Louis Hospital, Paris, France), the French Agency of Biomedicine (Paris) (Arrêté $n^{\circ} 2001 / 904$ and Ref: AG08-0321 GEN of 27/09/2008; www.agence-biomedecine.fr/Genetique) and the European Commission "Geneskin: Genetics of human genodermatosis" (Brussels, Belgium).

\section{Brazilian, English and American cohorts}

English (89 XPs) and Brazilian (32 XPs) cohorts were published [39, 44]. Up-to-date information concerning the American NIH xeroderma pigmentosum cohort [34, 45] (137 XPs) is a personal communication of Dr. K.H. Kraemer (NIH, Bethesda, USA).

\section{Results}

\section{Risk of development of internal tumors in XP patients Cohorts of XP patients}

We performed a meta-analysis and systematic review of 4 independent XP cohorts: 137 patients in the American NIH cohort (A-XP) with 14 internal tumors (10.2\%); 176 patients from France (F-XP) with 32 internal tumors (18.2\%); 32 patients from Brazil (B-XP) with 2 internal tumors (6.3\%) and 89 patients in the English cohort (UK-XP) with 2 internal tumors (2.2\%) (Table 1; Additional file 1: Figure S1A). These cohorts have been 
Table 1 Distribution of internal XP tumors and complementation groups* among the four independent XP cohorts

\begin{tabular}{|c|c|c|c|c|}
\hline \multirow[t]{2}{*}{ Tumor types ${ }^{\ddagger}$} & \multicolumn{4}{|l|}{ XP cohorts ${ }^{\dagger}$} \\
\hline & A-XP (137) (delTG) & F-XP (176) (delTG) & B-XP (32) (delTG) & UK-XP (89) (delTG) \\
\hline Breast & 0 & 1 & 0 & 0 \\
\hline CNS & 4 & $3(3)$ & 0 & 2 \\
\hline Gl & 0 & $1 X P-V$ & $1 \mathrm{XP}-\mathrm{V}$ & 0 \\
\hline HEM & $4(2)$ & $17(17)$ & 0 & 0 \\
\hline $\mathrm{Kl}$ & 0 & $1(1)$ & 0 & 0 \\
\hline LU & 3 & 0 & 0 & 0 \\
\hline THY & 2 (incl. 1 XP-E) & $3(3)$ & 0 & 0 \\
\hline Female & 1 & $5(5)$ & $1(1)$ & 0 \\
\hline Male & 0 & $1 \mathrm{XP}-\mathrm{V}$ & 0 & 0 \\
\hline Total & $14(2)$ & $32(29)$ & $2(1)$ & $2(0)$ \\
\hline
\end{tabular}

* All these internal tumors occurred in XP-C patients except for 4 patients indicated in the Table

${ }^{\dagger}$ A-XP, F-XP, B-XP and UK-XP refer to the American, French, Brazilian and English XP cohorts (see Methods)

${ }^{\ddagger}$ CNS refers to central nervous system, GI to gastro-intestinal, HEM to hematological malignancies, KI to kidney, LU to lung, THY to thyroid tumors, "Female" means tumor of the woman reproductive system and "Male" tumor of the man reproductive system

${ }^{\$}$ Number of XP patients carrying the founder delTG XPC mutation from North Africa [13]

independently set up to follow XP patients in terms of clinical, genetic and epidemiological studies without any bias concerning internal tumors.

\section{Risk of internal tumors in the 4-combined XP cohort}

To estimate frequencies and risks of internal tumors in XP population, we combined all 4-aforementioned cohorts into a unique one consisting of $434 \mathrm{XP}$ patients and including 50 internal tumors (for 49 XP patients). The XP patients develop internal tumors much more frequently than the American general population (11.3\% vs $0.47 \%, p$-value $=3.4 \mathrm{E}-58$; binomial test, two-sided) (Additional file 1: Figure S1A). The tumor spectrum in $\mathrm{XP}$ is characterized by an excess of hematological malignancies (HEM), central nervous system (CNS), thyroid (THY) and gynecological (FEM) tumors as compared to the general population (Fig. 1A). Ages of onset of internal tumors in combined XP cohort is significantly lower than in the general population (Fig. 1B).

The Odds ratio of developing internal tumors (excluding the tumors of reproductive systems that are treated separately by taking into account the gender information) for the $434 \mathrm{XP}$-cohort is $34(95 \% \mathrm{CI}=25-47$; $p$-value $=1.0 \mathrm{E}-47) \quad($ Table 2$)$. The particularly strong risks are observed for CNS, HEM, THY and FEM tumors (OR from 74 to 331; Table 2). Age stratification reveals highest risks of tumor onset at young ages of XP patients (0-20 years; OR: 665) (Table 2).

XP-C complementation group represents $54 \%$ of the 434 XPs-cohort, however $94 \%$ of the internal tumors occurred in XP-C (XP-C vs. non-XP-C; OR $=9.8,95 \%$
CI: $3.5-38.1$; two-sided Fisher test $p$-value $=3.4 \mathrm{E}-8$ ) (Table 1).

\section{Risk of internal tumors in the French cohort with the delTG $X P C$ mutation (from North African origin) vs the other XP populations}

The French XP cohort is composed of 176 patients including $113 \mathrm{XP}-\mathrm{C}$. The vast majority (80\%) originated from North Africa, belonged to consanguineous families and shared the same founder mutation: c.1643_1644 delTG; p.Val548AlafsX572 (called here XPC “delTG”). We previously estimated that this mutation appeared around 1250 years ago in North Africa indicating that all these patients should have common ancestors [13].

Eighteen \% of this French cohort (31 patients for 32 tumors) developed internal tumors (Table 1), demonstrating a 56-fold increased risk as compared to the general population ( $p$-value $=3.6 \mathrm{E}-35$ ) (Table 2). Among these 31 patients, 2 are XP-V (6.5\%) and 29 are XP-C (93.5\%) among which $28(90 \%)$ originated from North Africa, and carry the XPC delTG mutation: $59 \%$ are hematological malignancies, $17 \%$ gynecological tumors, $10 \%$ THY tumors and 10\% CNS tumors (Table 1). Genetic homogeneity of the French XP cohort and this high risk of internal tumors might introduce bias in the estimates of risks of internal tumors in the overall XP population. To control for this possibility, we reproduced all the previous analyses on the 3-combined cohorts after excluding the French one: all the results concerning the increased risk of internal tumors in XP are still observed. In the 3-combined cohorts (without the F-XP cohort) the 


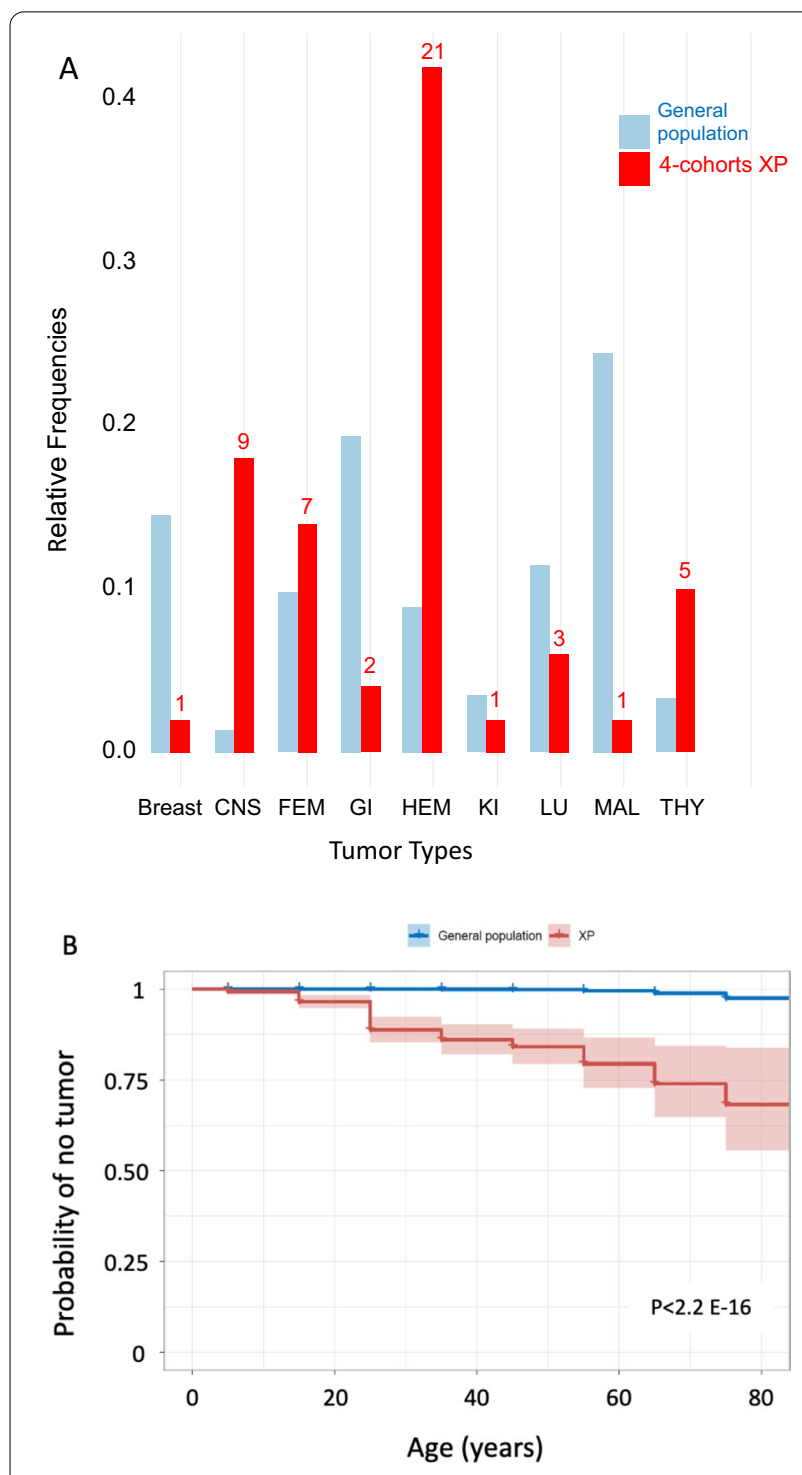

Fig. 1 Characteristics of XP patients reported in 4 independent XP cohorts. A. Spectrum of tumor types in the 50 tumors versus general population. Relative frequencies of XP internal tumor types (excluding skin cancers) in the grouped 4 XP cohorts (red) as compared to the general American population (blue). The red numbers correspond to the raw counts of XP tumors. One patient had two independent tumors. B. Kaplan-Meier plot with 95\% confidence intervals of the age of internal tumor onset in XP population versus the general population. The $p$-value is given as compared to the American general population

highest cancer risks are again observed for CNS, HEM, THY and FEM tumors (OR: 37-371); the most important risks are again for the young XPs and particularly the $\mathrm{XP}-\mathrm{C}$ group. At the same time, the French XP-Cs with the delTG mutation exhibit greater risks for all categories of tumors and ages, except for CNS tumors, which show lower Odds ratios than in the pooled 3 cohorts (Table 2).

\section{Risk of internal cancer in each independent XP cohort}

The Odds ratios of developing internal tumors (excluding the tumors of reproductive systems) in comparison to the general population are $56(95 \% \mathrm{CI}=37-84)$ for $\mathrm{F}-\mathrm{XP}$, $33(95 \% \mathrm{CI}=19-59)$ for $\mathrm{A}-\mathrm{XP}, 10(95 \% \mathrm{CI}=1.4-73)$ for $\mathrm{B}-\mathrm{XP}$ and $7(95 \% \mathrm{CI}=1.8-30)$ for UK-XP (Additional file 1: Figure S2A). This confirms the previous combined data analysis that the French XP-C are at a very high risk of developing internal tumors.

We stratified the XP cases by tumor types, ages and XP complementation groups, and revealed a particularly increased tumor risk in some categories. Odds ratios for CNS tumors are the highest in three cohorts: 469 for A-XP, 361 for UK-XP and 272 for F-XP. The Odds ratios for hematological malignancies are 253 for the F-XP cohort and 71 for the A-XP cohort. The risk for thyroid tumors is also high in F-XP and A-XP (111 and 94, respectively) (Additional file 1: Figure S2B) (95\% CI and $p$-values are indicated in the Additional file 1: Figure S2). $\mathrm{XP}$ patients aged $0-20$ years old exhibit an Odds ratio of 1330 for the F-XP and 594 for the A-XP (Additional file 1: Figure $\mathrm{S} 2 \mathrm{C}$ ). XP-C patients are at very high risk, particularly in the F-XP, A-XP and the UK-XP cohorts. They demonstrate the highest Odds ratios for developing CNS tumors and hematological malignancies in F-XP and A-XP cohorts (Additional file 1: Figures S3A, B).

The Odds ratios for the tumors of the reproductive systems are also high for the female F-XP (135), A-XP (32) and B-XP (120) corresponding mainly to uterine tumors; while the risk for male-related tumors was not statistically significant compared to the general population (Table 2 and Additional file 1: Figure S3C) (95\% CI and $p$-values are indicated in the Additional file 1: Figure S3).

\section{Description of all XP patients with internal tumors reported in the literature}

Additionally, case reports were published describing XP patients with internal tumors. Following PubMed search, we established an exhaustive list of 89 internal tumors developed by $88 \mathrm{XP}$ patients that corresponds to 79 tumors reported in the literature starting from 1958 up to 2020, one unreported tumor indicated to us by Dr. K.H. Kraemer for the American cohort (NIH, Bethesda, USA) and 9 unpublished tumors from the French XP cohort (reported here in Table 3 and Additional file 1: Table S1). The distributions of these patients according to gender and country of origins are indicated in Additional file 1: Tables S2 and S3. Of course, the 50 internal tumors described in the 4 well-characterized XP cohorts are part of these 89 reported internal tumors.

The tumor spectrum in the XP case reports is different from the general population for non-skin cancers (https://seer.cancer.gov). The most frequent are HEM 
Table 2 Risk (OR) of internal tumors according to tumor types, ages and complementation groups following combined analysis of the 4 XP cohorts and of only 3 cohorts excluding the French one (biased for the delTG XPC mutation) as well as the French cohort alone

\begin{tabular}{|c|c|c|c|c|c|c|c|c|c|c|}
\hline & \multicolumn{3}{|c|}{4 cohorts } & \multicolumn{3}{|c|}{$\begin{array}{l}3 \text { cohorts (French cohort } \\
\text { excluded) }\end{array}$} & \multicolumn{3}{|c|}{ French cohort } & \multirow{2}{*}{$\begin{array}{l}\text { French/other } 3 \text { cohorts } \\
\text { OR_F/OR_3cohorts }\end{array}$} \\
\hline & OR & $95 \% \mathrm{Cl}$ & $p$-value & OR & $95 \% \mathrm{Cl}$ & $p$-value & OR & $95 \% \mathrm{Cl}$ & $p$-value & \\
\hline All internal tumors & 34 & $25-47$ & $1.0 \mathrm{E}-47$ & 21 & $13-35$ & $4.9 \mathrm{E}-16$ & 56 & $37-84$ & $3.6 \mathrm{E}-35$ & 2.64 \\
\hline CNS & 331 & $171-641$ & $2.4 \mathrm{E}-20$ & 371 & $165-834$ & $2.7 \mathrm{E}-14$ & 272 & $87-853$ & $2.3 \mathrm{E}-07$ & 0.73 \\
\hline HEM & 120 & 77-186 & $3.7 E-36$ & 37 & $14-99$ & $5.4 \mathrm{E}-06$ & 253 & $154-418$ & $7.5 E-35$ & 6.84 \\
\hline $\mathrm{THY}$ & 74 & $31-179$ & $1.2 \mathrm{E}-08$ & 49 & 12-199 & $8.1 \mathrm{E}-04$ & 111 & $35-346$ & $3.4 \mathrm{E}-06$ & 2.24 \\
\hline FEM $^{*}$ & 91 & 42-193 & $3.5 \mathrm{E}-12$ & 50 & $6-187$ & $8.0 \mathrm{E}-4$ & 135 & $53-329$ & $6.9 \mathrm{E}-10$ & 2.7 \\
\hline$M A L^{*}$ & 9 & $1.3-69$ & 0.10 & - & - & - & 10 & $0.24-55$ & 0.1 & - \\
\hline Age 0-20 & 665 & $\begin{array}{l}368- \\
1200\end{array}$ & $4.3 E-30$ & 266 & $84-841$ & $2.5 \mathrm{E}-07$ & 1330 & $\begin{array}{l}654- \\
2701\end{array}$ & $1.9 E-25$ & 5.00 \\
\hline Age $21-40$ & 234 & $153-358$ & $1.5 E-47$ & 132 & $64-271$ & $6.0 \mathrm{E}-15$ & 381 & $221-655$ & $2.6 \mathrm{E}-35$ & 2.89 \\
\hline Age $41-60$ & 22 & $8-60$ & $4.8 \mathrm{E}-05$ & 25 & $8-82$ & $3.0 \mathrm{E}-04$ & 16 & $2-116$ & $6.5 \mathrm{E}-02$ & 0.62 \\
\hline Age $61-80$ & 7 & $2-30$ & $3.6 \mathrm{E}-02$ & 10 & $2-44$ & $1.9 \mathrm{E}-02$ & - & - & - & - \\
\hline$X P-C$ & 64 & $45-90$ & $3.9 E-54$ & 42 & $24-74$ & $3.9 E-18$ & 90 & 58-140 & $1.6 \mathrm{E}-38$ & 2.13 \\
\hline$X P-E$ & 36 & $5-281$ & $3.1 \mathrm{E}-02$ & 46 & $6-372$ & $2.5 \mathrm{E}-02$ & - & - & - & - \\
\hline$X P-V$ & 11 & $3-47$ & $1.4 \mathrm{E}-02$ & 12 & 2-91 & $8.1 \mathrm{E}-02$ & 11 & $1-78$ & $9.2 \mathrm{E}-02$ & 0.87 \\
\hline
\end{tabular}

* We had no access to the gender of XP patients from the UK cohort. Calculations have been made by using the three other XP cohorts

Same legend as in Table 1

(34\%), CNS (16\%), gynecological (13\%) and thyroid (9\%) tumors while in the general population these tumors only represent $8.9 \%, 1.3 \%, 9.8 \%$ and $3.3 \%$ of all tumors, respectively (Additional file 1: Figure S4A). This distribution is very similar to the one shown for the 4 international XP cohorts (Fig. 1A) indicating there is no distribution bias between the analyzed XP patients.

The median age at diagnosis of internal tumors in XP patients was significantly lower than in general population, 21 years vs. $\sim 65$ years, respectively (Additional file 1: Table S4) (Mann-Whitney-Wilcoxon two-sided Test $p$-value $<2.2 \mathrm{E}-16)$. The age at diagnosis of internal tumors in XPs varied between tumor types (Fig. 2). The median ages at diagnosis are 15 years for CNS tumors (range: 7-38) and 22.5 years for HEM (range: 3-36). Similar median ages are found for thyroid, head \& neck, kidney and gynecological tumors, while patients developing lung (58y), urological (60y) and digestive (50y) tumors are substantially older (Fig. 2 and Additional file 1: Table S4). For example, a 28-years difference of median ages at diagnosis is observed between hematological malignancies and digestive tumors in XP patients $\left(P=1.6 \mathrm{E}-5 X^{2}\right.$ test, Additional file 1: Figure S5).

Internal tumors are frequently lethal in XP patients (Additional file 1: Figure S4B). The median age of death is 25 years. For the patients with HEM the delay between diagnosis and death is an average of 2 years (range: $<1-10$ years) and for the CNS tumors, the average time is 1.5 years (range: $1-9$ years).
Among the 65 patients, for whom the mutated XP gene was identified, the $\mathrm{XP}-\mathrm{C}$ group is the most frequent (83\%), followed by XP-V (9\%) and XP-A (3\%) (Additional file 1: Table S2). Tumor types occurring at early ages in XP are almost exclusively associated with the XP-C group: the hematological malignancies $(92 \%$ are XP-Cs), CNS tumors (90\%), gynecological tumors (100\%) and thyroid cancers (86\%). However, this trend is not observed for digestive and urological cancers associated with later onset in XP (Additional file 1: Table S4).

In this studied collection of internal XP tumors, there were 37 (38 tumors) patients with identified delTG mutation representing $42 \%$ of the whole cohort and $69 \%$ of the XP-C patients (Additional file 1: Table S2). At the same time, hematological malignancies, gynecological and thyroid tumors in delTG patients represented $81 \%, 80 \%$ and $71 \%$ of known complementation groups, confirming the increased risk of these malignancies in the XP-C delTG patients as compared to the remaining XP cohort. The highest risk for XP-C patients with another germline mutation than delTG is for CNS tumors (Additional file 1: Table S4).

\section{Discussion}

To calculate the risk factors of XP patients to develop internal tumors, we made use of 4 very-well characterized XP cohorts from different countries and different laboratories. The Odds ratio for all classes of internal tumors is 34 for the pooled $4 \mathrm{XP}$ cohorts and can go as 


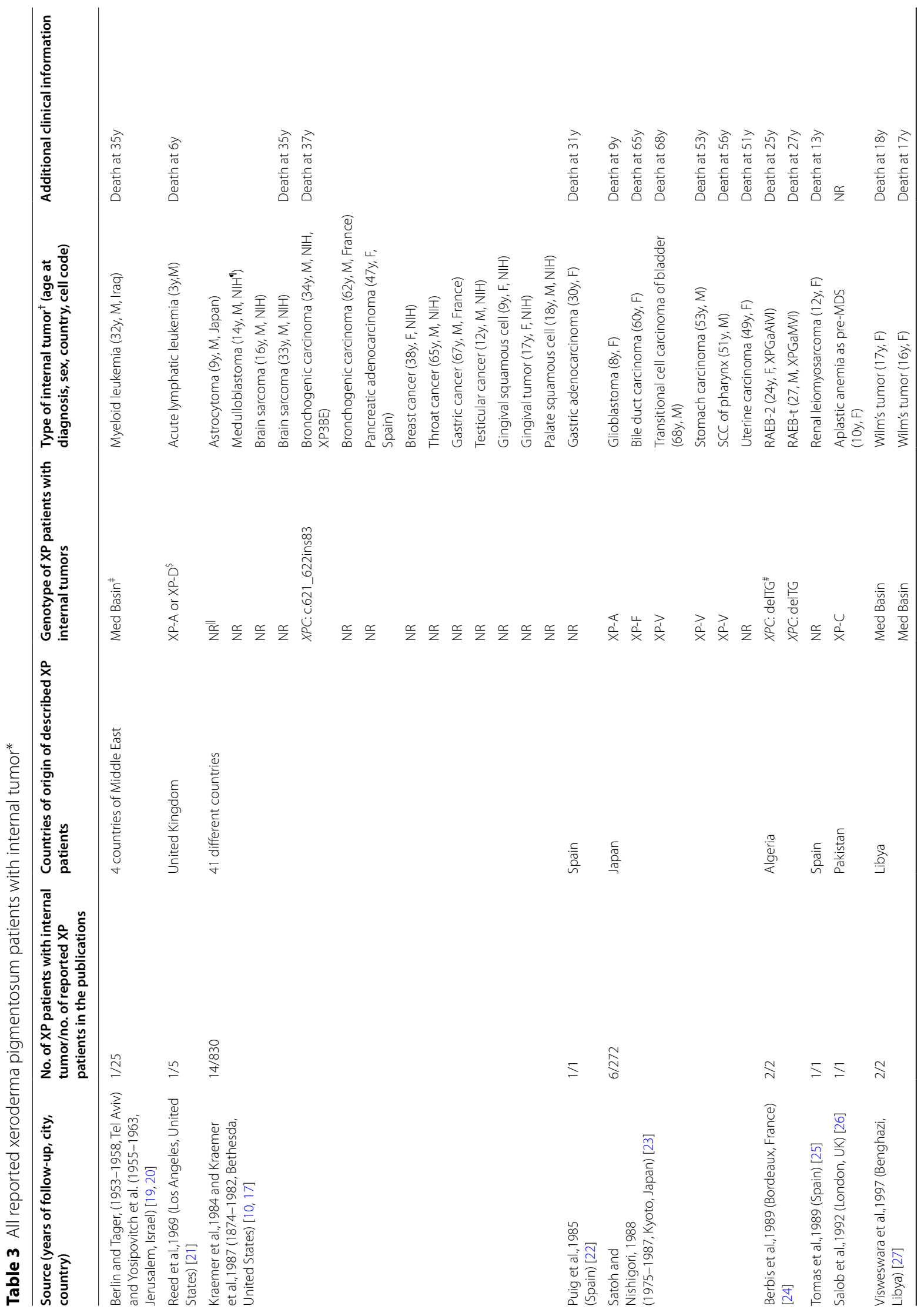




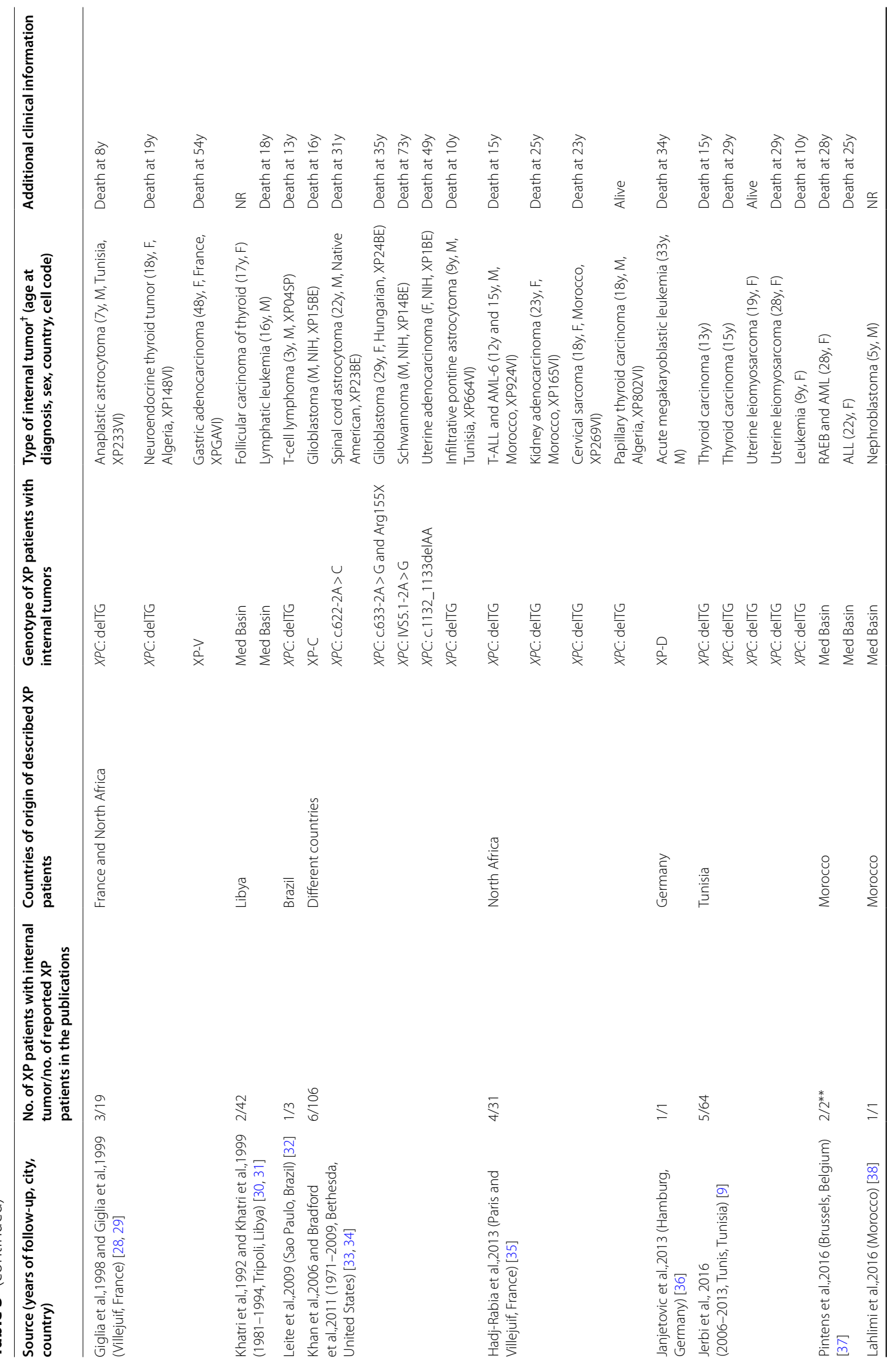




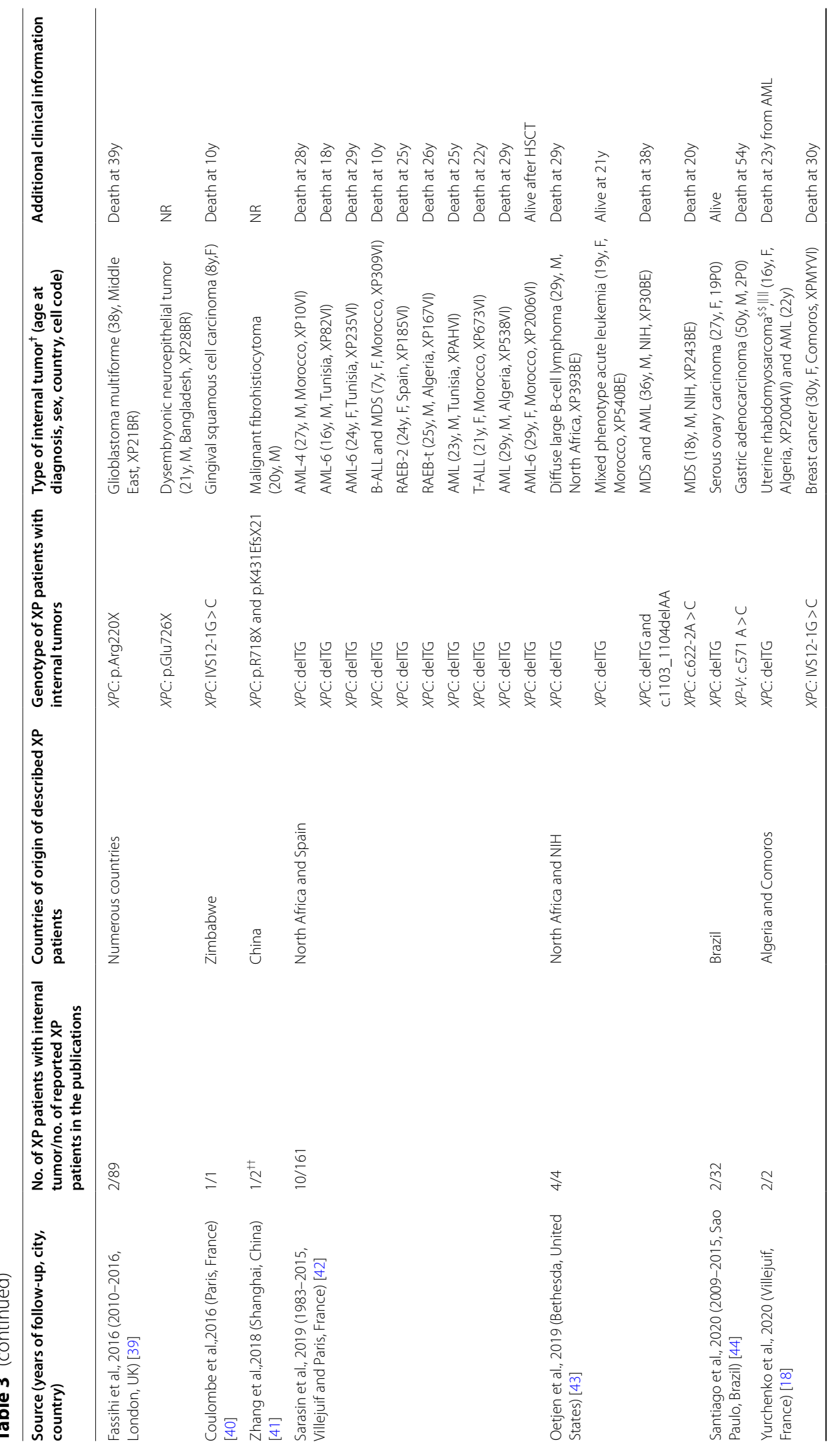




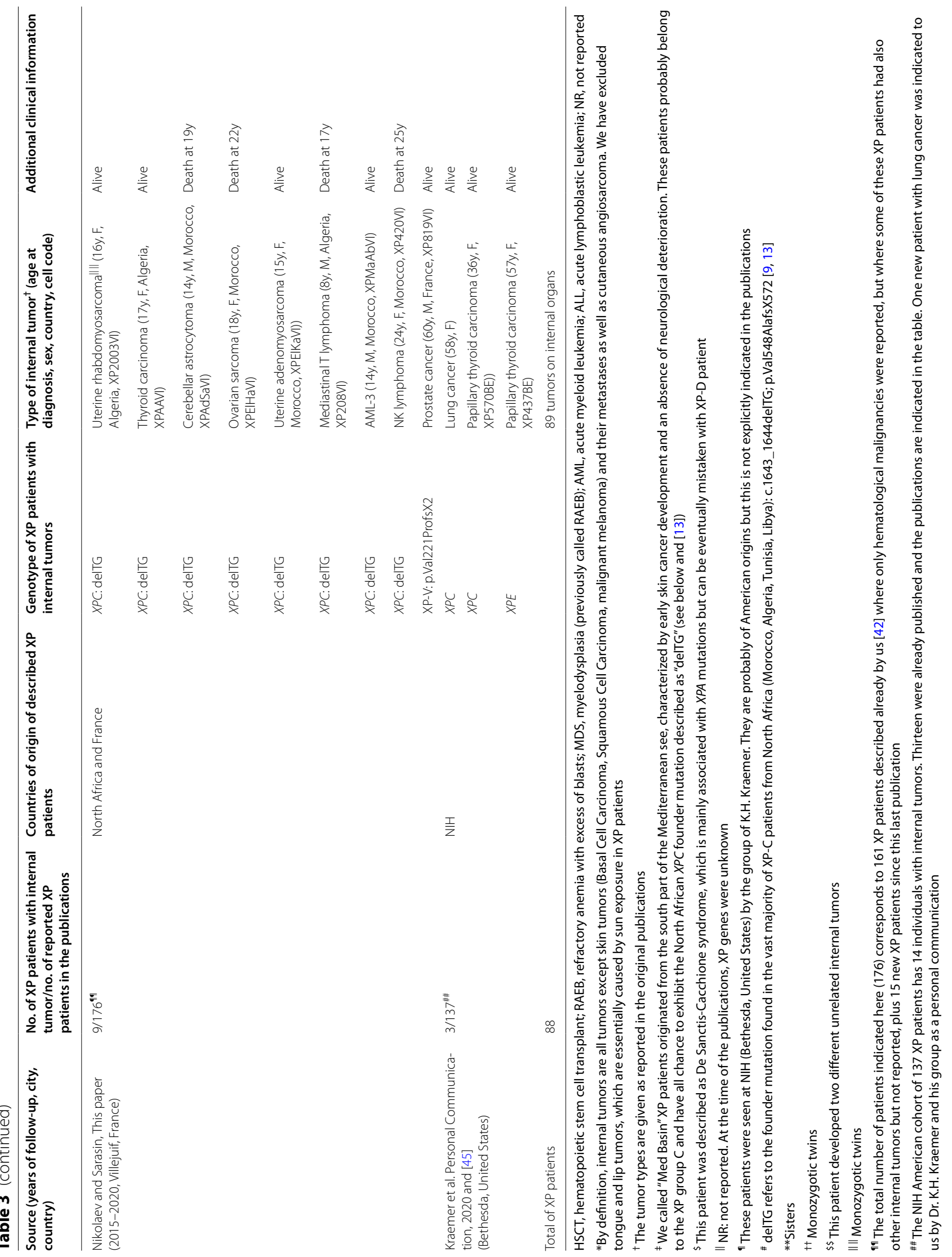




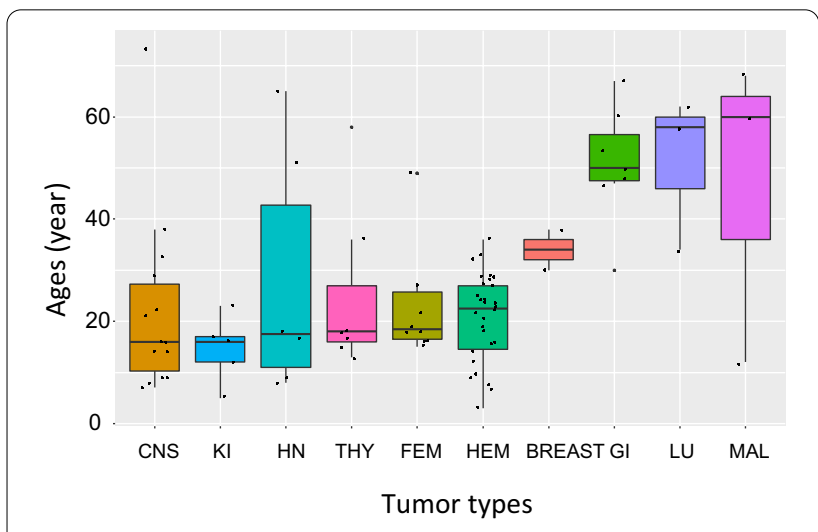

Fig. 2 Ages of diagnosis (when known) of internal tumors in all reported XP patients grouped by tumor types. Each black point represents the age at diagnosis for one XP patient with internal tumor. CNS: central nervous system; KI: kidney; HN: head and neck; THY thyroid; FEM: female-reproductive system related tumor; HEM: hematological malignancies; Gl: gastro-intestinal; LU: lung; MAL: male-related tumor. The unique Fibrohistiocytoma is not indicated here

high as 331 folds for CNS, tumors, 120 folds for HEM and to more than 600 folds for XP patients aged up to 20 years old (Table 2). We calculated the risk factors by comparison with the American general population because the American XP patients represent 32\% of the combined cohorts and the American registry of cancer incidence (SEER database) is very comprehensive and well-maintained. Therefore, this use of cancer incidence statistics of the American general population, as a control group for non-US XP cohorts, might cause biases in the estimates of their relative cancer risk as the corresponding populations might be different from the US-population by susceptibility to some cancer types.

Several transgenic mice with germline mutations on XP genes have been constructed. Interestingly enough, internal tumors such as liver, lung cancers or lymphomas are frequently developed in these different XPmouse models confirming the role of NER deficiency in internal cancers [46] (Supporting Methods and Additional file 1: Table S5) and corroborate human findings.

Among the 4-analyzed XP cohorts, the French one is predominantly associated with one founder mutation in the $X P C$ gene which makes it a homogeneous cohort. The reported delTG mutation gives rise to a stop codon and a total absence of the XPC protein, as already described [13]. However, most of the reported $X P C$ mutations also give rise to stop codons and did not appear to be associated with a high level of internal cancers. So, a combination of this specific mutation and ethnicity of the patients should be involved in their high risk to develop internal tumors.
Predisposition to hematological malignancies was one of the most pronounced features in young XP patients. The types of hematological malignancies in XP were different from typical sporadic MDS/AML but resembled tumors in patients previously-treated by chemotherapy for a first cancer [42], although the young XP patients were not treated by any anti-tumoral protocol before tumor diagnosis. This similarity suggests that young XPs have rapidly accumulated spontaneous DNA lesions that were not repaired due to NER deficiency. We have recently reported that the mutation load was more than 25-fold higher in XP-C hematological malignancies than in the same tumor types in the general population with a very strong bias toward mutations located on nontranscribed strands [18]. The somatic mutations found in XP-C leukemias closely resemble COSMIC signature $8[18,47]$ that suggests the presence of unrepaired spontaneous purine DNA lesions probably induced by an endogenous oxidative process [18, 29, 48-51].

The high predisposition to hematological malignancies of XP-C patients carrying the North-African germline mutation is also observed in the American cohort (Odds ratio: $74 ; p$ value $=7.0 \mathrm{E}-14$; Fisher exact two-sided test) and remains unexplained. Whole exome sequencing of DNA in several patients and their parents did not show any additional pathogenic DNA variants that could be potentially implicated in predisposition to leukemia [42]. We thoroughly searched for additional modifier variants in the genomes and exomes of delTG patients with leukemia (see Additional file 1: Supporting Methods). We identified only one Identical by Descent Segment in all patients. The region of intersection spans $1.02 \mathrm{Mb}$ and includes 13 genes including XPC. Besides delTG mutations there were no common or unique pathogenic mutations in these genes (Additional file 1: Figure S6). This analysis reduces the possibility that a common genetic variant in Mediterranean XP-C patients with delTG mutation be responsible for increased risk of leukemia in this cohort.

The patients' lifestyle with North-African traditions and food may be exacerbating potential internal DNA damage $[9,13]$. For example, charcoaled foods used in North Africa are known to produce genotoxic molecules, such as Acrolein that leads to exocyclic mutagenic dG damage [52]. Additionally, the powerful mutagen Aflatoxin B1, known to induce DNA lesions at Gs that are repaired by NER [48], is present in the food in Africa and induces liver cancers. It is plausible that other types of genotoxic contaminants in food from North Africa might be carcinogenic for XP-C patients. Another possibility is that sun-exposure induces some kind of general oxidative stress that will produce DNA lesions not repaired by delTG XP-C patients. Indeed, 
the XPC protein has also been involved in other DNA repair pathways such as Base Excision Repair [12, 49].

\section{Conclusion}

It is essential that the physicians who treat XP patients be aware of this strong predisposition since XP patients now live longer due to better sun-protection and better knowledge of the disease [53]. The importance of early diagnosis of CNS, thyroid and gynecological cancers and HEM cannot be over-emphasized. The MDS/AML occurring in XP-C patients often appeared following several years of anemia [42] that should be searched for by a regular annual blood analysis starting around the age of 10. Regular gynecological exams and thyroid echography are easy to perform on a regular basis.

\section{Supplementary Information}

The online version contains supplementary material available at https://doi. org/10.1186/s13023-022-02203-1.

Additional file 1: Table S1. Distribution of internal tumors of all reported XP patients according to organs, complementation groups, ages at diagnosis and death Table S2. Distribution of the complementation groups of all reported XP patients with internal tumors Table S3. Countries of familial origins of all reported XP patients with internal tumors Table S4. Characteristics of internal tumors according to the complementation group of all reported XP patients. Table S5. Risk (OR) of internal tumors in mouse XP gene-knockout experiments without exogeneous mutagens Fig. S1. Percent of XP patients with internal tumors in the 4 independent XP cohorts Fig. S2. Odds Ratio for internal tumor risk in XP patients as compared to the American general population stratified by each individual cohort, tumor types and patient ages. Fig. S3. Odds Ratio for internal tumor risk in XP patients as compared to the American general population stratified by complementation groups, tumor types and reproductive system-related tumors. Fig. S4. Relative frequencies of XP internal tumor, tumor occurrence and survival in all reported XP patients. Fig. S5. Probability of the absence of internal tumors in XP patients stratified between digestive cancers and hematological malignancies. Fig. S6. Analysis of the common haplotypes in XP-C delTG patients with leukemia. Supporting References.

\section{Acknowledgements}

The authors are particularly thankful to Dr. Kenneth H. Kraemer (Bethesda, USA) and his group (Dr. John J. DiGiovanna, Dr. Deborah Tamura, Dr. Sikandar G. Khan and Dr. Elizabeth Rizza) for giving us the information concerning the new unpublished XP patients with internal tumors in the $\mathrm{NIH}$ xeroderma pigmentosum cohort. Similarly, we are thankful to Dr. Chikako Nishigori (Kobe, Japan) for sending us unpublished data on internal tumors in some Japanese $\mathrm{XP}$ patients. We are also thankful to the numerous physicians following XP patients for discussion and clinical information and to the collaboration of patients and their families as well to the support of the French XP association "Les Enfants de la Lune" (Bellegarde-sur-Valserine, France).

\section{Authors' contributions}

AS designed research; SN and AY analyzed data; and AS and SN wrote the paper. All authors read and approved the final manuscript.

\section{Funding}

This work was supported by the Foundation ARC 2017, Foundation Gustave Roussy and Swiss Cancer League KFC-3985-08-2016 to SN.

\section{Availability of data and materials}

The authors confirm that the data supporting the findings of this study are available within the article and its Additional files.

\section{Declarations}

Ethics approval and consent to participate

Obtained and reported in Method.

\section{Consent for publication}

Not applicable.

\section{Competing interests}

The authors declare that they have no competing interests.

Received: 16 September 2021 Accepted: 30 January 2022 Published online: 04 March 2022

\section{References}

1. Hanawalt PC, Spivak G. Transcription-coupled DNA repair: two decades of progress and surprises. Nat Rev Mol Cell Bio. 2008;9(12):958-70.

2. Lehmann AR, McGibbon D, Stefanini M. Xeroderma pigmentosum. Orphanet J Rare Dis. 2011;6:70.

3. Sarasin A. UVSSA and USP7: new players regulating transcription-coupled nucleotide excision repair in human cells. Genome Med. 2012;4(5):44-5.

4. Kleijer WJ, et al. Incidence of DNA repair deficiency disorders in western Europe: Xeroderma pigmentosum, Cockayne syndrome and trichothiodystrophy. DNA Repair (Amst). 2008;7(5):744-50.

5. Robbins $\mathrm{JH}$, Kraemer KH, Lutzner A et al. Xeroderma pigmentosum. An inherited disease with sun sensitivity, multiple cutaneous neoplasms, and abnormal DNA repair. Ann Intern Med. 1974; 80(2):221-48.

6. Takebe H, Nishigori C, Satoh Y. Genetics and skin cancer of xeroderma pigmentosum in Japan. Jpn J Cancer Res. 1987;78(11):1135-43.

7. Bhutto AM, Shaikh A, Nonaka S. Incidence of xeroderma pigmentosum in Larkana, Pakistan: a 7-year study. Br J Dermatol. 2005;152(3):545-51.

8. Cartault $F$ et al. A new XPC gene splicing mutation has lead to the highest worldwide prevalence of xeroderma pigmentosum in black Mahori patients. DNA Repair (Amst.) 2011; 10(6):577-85.

9. Jerbi M, et al. Clinical, genealogical and molecular investigation of the xeroderma pigmentosum type C complementation group in Tunisia. Br J Dermatol. 2016;174(2):439-43.

10. Kraemer KH, Lee MM, Scotto J. Xeroderma pigmentosum. Cutaneous, ocular, and neurologic abnormalities in 830 published cases. Arch Dermatol. 1987; 123(2):241-50.

11. Cleaver JE. Cancer in xeroderma pigmentosum and related disorders of DNA repair. Nat Rev Cancer. 2005;5(7):564-73.

12. Hoeijmakers JH. DNA damage, aging, and cancer. New Engl J Med. 2009;361(15):1475-85.

13. Soufir N, et al. A prevalent mutation with founder effect in xeroderma pigmentosum group C from north Africa. J Invest Dermatol. 2010;130(6):1537-42.

14. Kumar N, Moreno NC, Feltes BC et al. Cooperation and interplay between base and nucleotide excision repair pathways: from DNA lesions to proteins. Genet Mol Biol. 2020; 43:e20190104.

15. Stary A, Kannouche P, Lehmann AR et al. A. Role of DNA polymerase eta in the UV mutation spectrum in human cells. J Biol Chem. 2003; 278(21):18767-75.

16. Opletalova K, et al. Correlation of phenotype/genotype in a cohort of 23 xeroderma pigmentosum-variant patients reveals 12 new diseasecausing POLH mutations. Hum Mutat. 2014;35(1):117-28.

17. Kraemer $\mathrm{KH}$, Lee MM, Scotto J. DNA repair protects against cutaneous and internal neoplasia: evidence from xeroderma pigmentosum. Carcinogenesis. 1984;5(4):511-4.

18. Yurchenko AA, et al. XPC deficiency increases risk of hematologic malignancies through mutator phenotype and characteristic mutational signature. Nat Commun. 2020;11(1):5834. 
19. Berlin C, Tager A. Xeroderma pigmentosum; report of eight cases of mild to moderate type and course: a study of response to various irradiations. Dermatologica. 1958;116(1):27-35.

20. Yosipovitch Z, Sachs MI, Neuman Z. Multiple malignant tumour formation in xeroderma pigmentosum. Br J Plast Surg. 1965;18:314-22.

21. Reed WB, Landing B, Sugarman G et al. Xeroderma pigmentosum. Clinical and laboratory investigation of its basic defect. JAMA. 1969; 207(11):2073-79.

22. Puig L, Martí R, Matías-Guiu X, et al. Gastric adenocarcinoma in a patient with xeroderma pigmentosum. Br J Dermatol. 1985;113(5):632-3.

23. Satoh Y, Nishigori C. Xeroderma pigmentosum: clinical aspects. Gann Monogr Cancer Res. 1988;35:113-26.

24. Berbis $P$, et al. Xeroderma pigmentosum and refractory anaemia in two first cousins. Br J Dermatol. 1989;121(6):767-71.

25. Tomás M, Salinas AS, Moreno J, et al. Renal leiomyosarcoma associated with xeroderma pigmentosum. Arch Esp Urol. 1989;42(5):484-6.

26. Salob SP, Webb DK, Atherto DJ. A child with xeroderma pigmentosum and bone marrow failure. Br J Dermatol. 1992;126(4):372-4.

27. Visweswara RN, Osman AR, Majeed SA et al. Xeroderma pigmentosum with adult Wilms' tumour. A rare association. Scand J Urol Nephrol. 1997; 31(6):569-71.

28. Giglia G, et al. p53 mutations in skin and internal tumors of xeroderma pigmentosum patients belonging to the complementation group $\mathrm{C}$. Cancer Res. 1998:58(19):4402-9.

29. Giglia $\mathrm{G}$, et al. Molecular analysis of glioma and skin-tumour alterations in a xeroderma-pigmentosum child. Int J Cancer. 1999;81(3):345-50.

30. Khatri ML, Shafi M, Mashina A. Xeroderma pigmentosum. A clinical study of 24 Libyan cases. J Am Acad Dermatol. 1992; 26(1):75-8.

31. Khatri ML, Bemghazil M, Shafi M, et al. Xeroderma pigmentosum in Libya. Int J Dermatol. 1999;38(7):520-4.

32. Leite RA, et al. Identification of XP complementation groups by recombinant adenovirus carrying DNA repair genes. J Invest Dermatol. 2009;129(2):502-6.

33. Khan SG, et al. Reduced XPC DNA repair gene mRNA levels in clinically normal parents of xeroderma pigmentosum patients. Carcinogenesis. 2006;27(1):84-94.

34. Bradford PT, et al. Cancer and neurologic degeneration in xeroderma pigmentosum: long term follow-up characterises the role of DNA repair. J Med Genet. 2011;48(3):168-76.

35. Hadj-Rabia S, et al. Unexpected extradermatological findings in 31 patients with xeroderma pigmentosum type C. Br J Dermatol. 2013;168(5):1109-13.

36. Janjetovic $S$, et al. Acute megakaryoblastic leukemia in a patient with xeroderma pigmentosum: discussion of pathophysiological, prognostic, and toxicological aspects. Acta Haematol. 2013;129(2):121-5.

37. Pintens $S$, Pierret $L$, Keymolen $K$, et al. Xeroderma pigmentosum and leukaemia in two sisters. J Eur Acad Dermatol Venereol. 2016:30:e42-3.

38. Lahlimi F, Harif M, Elhoudzi J. Nephroblastoma and xeroderma pigmentosum: a rare association. Arch Pediatr. 2016;23(1):75-7.

39. Fassihi $\mathrm{H}$ et al. Deep phenotyping of 89 xeroderma pigmentosum patients reveals unexpected heterogeneity dependent on the precise molecular defect. Proc Natl Acad Sci USA. 2016; 113(9):E1236-45.

40. Coulombe J, Orbach D, Soufir N, et al. Primary gingival squamous cell carcinoma in a xeroderma pigmentosum type C patient. J Eur Acad Dermatol Venereol. 2016;30(11):e157-8.

41. Zhang SD, et al. Monozygotic twins with group C xeroderma pigmentosum due to a compound heterozygous mutation in XPC gene. J Dermatol. 2019;46(3):e80-1.

42. Sarasin A, et al. Familial predisposition to TP53/complex karyotype MDS and leukemia in DNA repair-deficient xeroderma pigmentosum. Blood. 2019;133(25):2718-24.

43. Oetjen KA, et al. Predisposition to hematologic malignancies in patients with xeroderma pigmentosum. Haematologica. 2020;105(4):e144-6.

44. Santiago KM, et al. Comprehensive germline mutation analysis and clinical profile in a large cohort of Brazilian Xeroderma pigmentosum patients. J Eur Acad Dermatol Venereol. 2020;34(10):2392-401.

45. Kouatcheu SD, et al. Thyroid nodules in xeroderma pigmentosum patients: a feature of premature aging. J Endocr Invest. 2021;44(7):1475-82
46. Eppig JT. Mouse genome informatics (MGI) resource: genetic, genomic, and biological knowledgebase for the laboratory mouse. ILAR J. 2017:58:17-24.

47. Alexandrov LB, et al. Signatures of mutational processes in human cancer Nature. 2013;500(7463):415-21.

48. Sarasin AR, Smith CA, Hanawalt PC. Repair of DNA in human cells after treatment with activated aflatoxin B1. Cancer Res. 1977;37(6):1786-93.

49. D'Errico $M$, et al. New functions of XPC in the protection of human skin cells from oxidative damage. EMBO J. 2006;25(18):4305-15.

50. Cleaver JE, Revet I. Clinical implications of the basic defects in Cockayne syndrome and xeroderma pigmentosum and the DNA lesions responsible for cancer, neurodegeneration and aging. Mech Ageing Dev. 2008; 129(7-8):492-7.

51. Giglia-Mari G, Sarasin A. TP53 mutations in human skin cancers. Hum Mutat. 2003;21(3):217-28.

52. Moghe A et al. Molecular mechanisms of Acrolein Toxicity: Relevance to Human Disease Toxicol Sci. 2015; 143(2):242-55.

53. Walburn J, et al. Psychological correlates of adherence to photoprotection in a rare disease: International survey of people with Xeroderma Pigmentosum. Br J Health Psycho. 2019;24(3):668-86.

\section{Publisher's Note}

Springer Nature remains neutral with regard to jurisdictional claims in published maps and institutional affiliations.

Ready to submit your research? Choose BMC and benefit from

- fast, convenient online submission

- thorough peer review by experienced researchers in your field

- rapid publication on acceptance

- support for research data, including large and complex data types

- gold Open Access which fosters wider collaboration and increased citations

- maximum visibility for your research: over $100 \mathrm{M}$ website views per year

At BMC, research is always in progress.

Learn more biomedcentral.com/submissions 